\title{
Occiput-cervical fusion for symptomatic atlantoaxial subluxation in a 32-month-old child with Down syndrome: a case report
}

\author{
Sheng-Hong Tseng and Yun Cheng \\ Department of Surgery, National Taiwan University Hospital, 7 Chung-Shan S. Rd., Taipei 100, Taiwan
}

\begin{abstract}
Atlantoaxial subluxation in Down syndrome rarely becomes neurologically symptomatic in very young children. The authors present a 32-month-old girl with Down syndrome, who had tetraporesis due to an atlantoaxial subluxation. She was treated with halo immobilization and partial reduction of the subluxation at first, followed by removal of posterior arch of the atlas and posterior fusion with wire fixation. Halo immobilization was continued for 3 months after operation. After 1-year follow-up, her motor functions were normal, and the dynamic roentgenogram of the cervical spines showed good stability. The authors recommend posterior fusion and postoperative halo immobilization for the treatment of the symptomatic atlantoaxial subluxation in young Down syndrome patients, even in a 32-month-old child.
\end{abstract}

Keywords: atlantoaxial subluxation; Down syndrome; halo immobilization; surgery; young children

\section{Introduction}

Atlantoaxial subluxation for patients with the Down syndrome often becomes symptomatic at the age of $4-$ 30 years old, and is usually treated by posterior arthrodesis and postoperative external immobilization. ${ }^{1,2}$ However, there is no report about the surgical treatment for the symptomatic subluxation in patients younger than 3 years old in English literature. In this report, the authors present experience of the management of symptomatic atlantoaxial subluxation in a $32-$ month-old girl with Down syndrome.

\section{Case report}

This 32-month-old girl had the typical features of Down syndrome and had mild growth and developmental delay after birth. Two months prior to admission, she had head tilt and right limb weakness. On admission, her head was tilted to the right with slight rotation. Muscle power was grade $1 / 5$ of the right upper and lower limbs, and $3 / 5$ for the left limbs. The deep tendon reflexes were increased in all four limbs, and the plantar responses were extensor. Pinprick sensation was decreased below neck level. Dynamic studies of the cervical spine roentgenogram revealed atlantoaxial subluxation and rotation, without definite occipitoatlantal instability (Figure 1). Magnetic resonance imaging study revealed C1-2 subluxation with marked spinal cord compression at the level of the foramen magnum (Figure 2). Under general anesthesia, the affected region was immobilized with a halo vest using 8 screws with 2.5 in-lb of insertional torque. The

Correspondence: S-H Tseng subluxation was partially reduced by adjusting the halo under the guide of fluoroscope. After reduction muscle power improved to grade $4 / 5$ bilaterally. Wire fixation and fusion were performed $1 / 2$ month later, the posterior arch of the atlas was removed because it impacted on the posterior rim of the foramen magnum and compressed the spinal cord from the dorsal aspect. The occiput, C2, and C3 were fixed with sublaminar wiring and fused by autogenous rib grafts - as those were near the operation field and easy to get. Although only partial reduction of the subluxation was obtained, removal of the posterior arch of the atlas provided
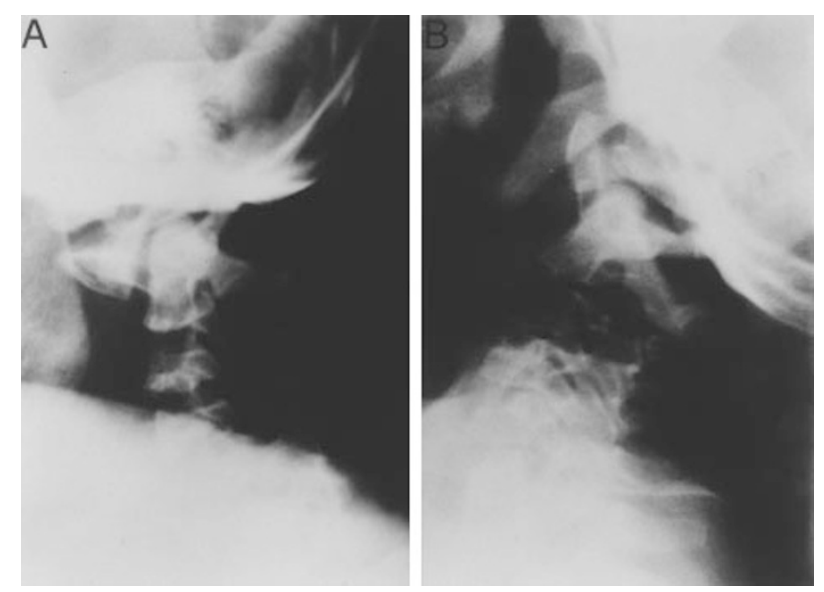

Figure 1 Lateral views of the preoperative dynamic roentgenogram during flexion $(\mathbf{A})$ and extension $(\mathbf{B})$ of the cervical spines, showing atlantoaxial subluxation and rotation 
adequate decompression of the spinal cord. After the operation the halo immobilization was continued for 3 months. Two screws over the right parietal area were loosened 1.5 and 2 months after operation, and were removed and another one was applied more posteriorly to strengthen the fixation. Muscle power became normal, and she could walk independently 3 months after operation. She was well after 1-year follow-up. Dynamic cervical spine roentgenogram revealed good stability (Figure 3).

\section{Discussion}

This patient was only 32-months-old, younger than the usual age of occurrence of symptomatic atlantoaxial subluxation in those who have Down syndrome. ${ }^{1}$

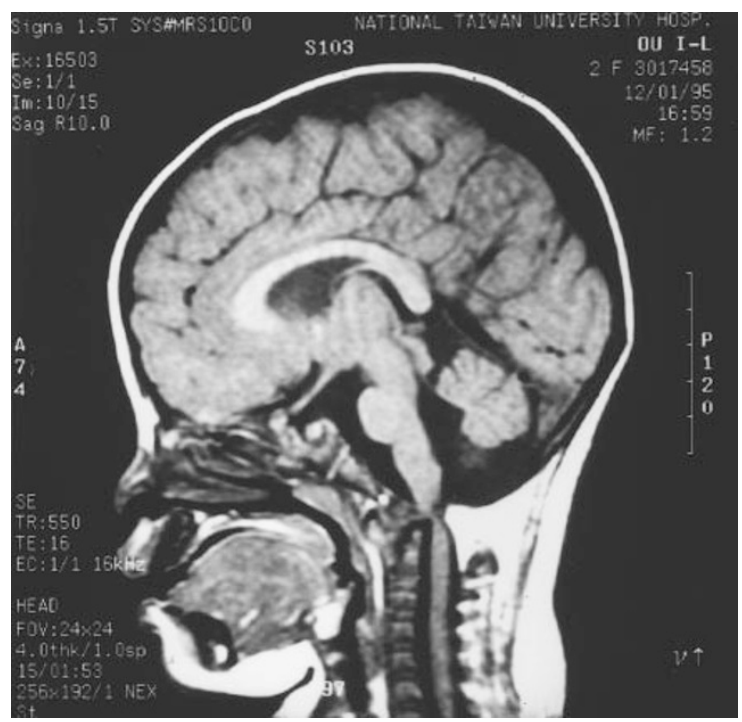

Figure 2 T1 weighted magnetic resonance imaging of the cervical spines, showing atlantoaxial subluxation with marked spinal cord compression
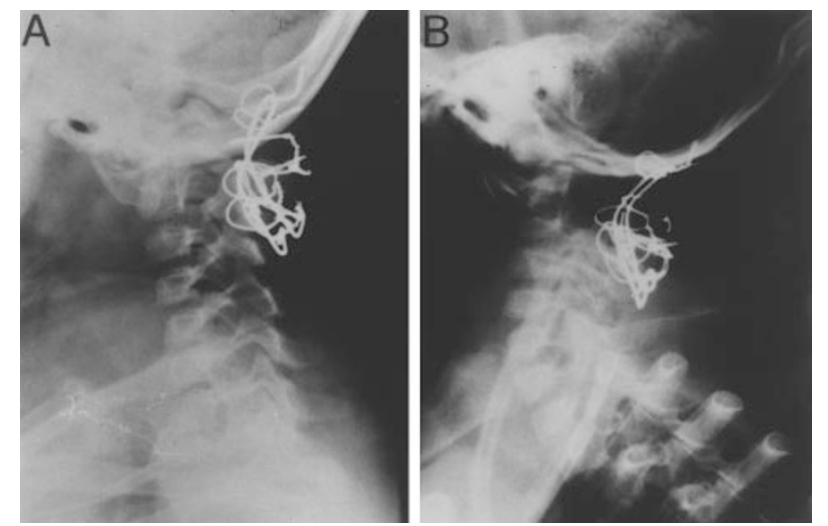

Figure 3 Lateral views of the dynamic roentgenogram during flexion (A) and extension (B) of the cervical spines 1 year after operation, showing wire fixation and good stability of the occiput and C2-3 spines
Surgical treatment for reduction of the subluxation, fixation and fusion are mandatory for symptomatic cases. ${ }^{1,3-6}$ Patients usually have a favorable neurological recovery after surgery,,$^{3-5,10}$ as occurred in our patient. Without arthrodesis, external immobilization only was inadequate for stability in patients with a Down syndrome, as ligament laxity is the main problem. ${ }^{1,3-6}$ Accompanying the arthrodesis, postoperative immobilization is very important for solid bony union. ${ }^{1-3,5}$ The halo is a good external immobilization device and is widely used for older children and adults. ${ }^{7-9}$ However, it was very difficult to expect an active young child to cooperate and move carefully under the restriction of the halo. In addition, the $\mathrm{C} 1-2$ region became less stable when the posterior arch of the atlas was removed.

Therefore, we used a more rigid fixation including wire fixation, bone grafts, and external immobilization in our patient. The halo has a high complication rate in young children, ${ }^{7}$ and is seldom used in patients younger than 3 years of age. ${ }^{9}$ Therefore, careful evaluation by skull osteology study and multiple-screw techniques are necessary to make the application of the halo easy and safe. ${ }^{7-9,11}$ In our patient, halo immobilization was successfully achieved by using multiple screws with low insertional torque. Although two screws were loosened and removed, the immobilization was maintained by applying another screw. In the English literature, only three Down syndrome patients with atlantoaxial subluxation had an operation before 4 years old, and all were older than 3 years. ${ }^{2,3,10}$ A 39-month-old girl received instrumental $\mathrm{C} 1-2$ posterior fusion with a one-piece cervical device and iliac bone grafts, and postoperative immobilization with a hard plastic cervical corset. $^{2}$ Another 44-month-old girl had halo ring traction under general anesthesia and dorsal occipitocervical fusion with full thickness rib graft and subsequent halo vest immobilization. ${ }^{3}$ Both patients made a good neurological recovery. Similarly, a 48-month-old girl was treated with posterior arthrodesis and postoperative halo immobilization. ${ }^{10}$ However the surgical indication was controversial as the patient had only neck pain without any neurological deficit before operation. ${ }^{10}$ Overall, authors recommend posterior fusion and postoperative halo immobilization for the treatment of symptomatic atlantoaxial subluxation in young Down syndrome patients, even in a 32-month-old child.

\section{References}

1 Chaudhry V, Sturgeon C, Gates AJ, Myers G. Symptomatic atlantoaxial dislocation in Down's syndrome. Ann Neurol 1987; 21: $606-609$.

2 Kohno $\mathrm{M}$ et al. Instrumentational posterior fusion for atlantoaxial subluxation in a young child with Down's syndrome. Case report. Neurol Med Chir (Tokyo) 1995; 35: 753-758.

3 Menezes AH, Ryken TC. Craniovertebral abnormalities in Down's syndrome. Pediatr Neurosurg 1992; 18: 24-33. 
4 Pueschel SM et al. Symptomatic atlantoaxial subluxation in persons with Down syndrome. J Pediatr Orthop 1984; 4: 682 688.

5 Rizzolo S, Lemos MJ, Mason DE. Posterior spinal arthrodesis for atlantoaxial instability in Down syndrome. J Pediatr Orthop 1995; 15: $543-548$.

6 Segal LS et al. Complications of posterior arthrodesis of the cervical spine in patients who have Down syndrome. $J$ Bone and Joint Surg 1991; 73-A: 1547-1554.

7 Dormans JP, Criscitiello AA, Drummond DS, Davidson RS. Complications in children managed with immobilization in a halo vest. J Bone and Joint Surg 1995; 77-A: 1370-1371.
8 Letts M, Kaylor D, Gouw G. A biomechanical analysis of halo fixation in children. J Bone and Joint Surg 1988; 70-B: $277-279$.

9 Mubarak SJ et al. Halo application in the infant. $J$ Pediatr Orthop 1989; 9: $612-614$.

10 Shikata $\mathbf{J}$ et al. Atlanto-axial subluxation in Down syndrome. Int Orthop 1989; 13: $187-192$.

11 Garfin SR et al. Skull osteology as it affects halo pin placement in children. J Pediatr Orthop 1986; 6: $434-436$. 